\title{
REVISÃO
}

\section{PATOLOGIA DA FORMA AGUDA, TOXÊMICA, DA ESQUISTOSSOMOSE MANSONI}

\section{Pedro Raso, Enio Roberto Pietra Pedroso e Jayme Neves}

\section{FASE AGUDA}

Entende-se por fase aguda as manifestações anátomo-clínicas da doença que ocorrem nos primeiros momentos da infecção. Na maioria dos pacientes, os sintomas clínicos são escassos e muitas vezes passam despercebidos. Numa minoria de casos, entretanto, adquire fisionomia especial, geralmente grave, com manifestações clínicas e anátomo-patológicas peculiares, constituindo a forma aguda toxêmica.

Forma aguda toxêmica (FAT). Acomete cerca de $0.3 \%$ dos esquistossomóticos das areas endèmicas ${ }^{26}$. Desconhecemos muitos dos mecanismos intimos que comandam a FAT, como a razão de tão baixa freqüência, os fatores responsáveis pelo seu aparecimento, o papel exato da imunidade celular e humoral durante a sua evolução, etc.

A forma aguda, com manifestações toxêmicas ou não, pode ser dividida em duas fases: pré e póspostural.

1. Fase pré-postural. Caracteriza-se pelas modificações anátomo-funcionais provocadas pelas cercárias, esquistossômulos e vermes adultos, antes da postura dos ovos. Inicia-se pela penetração ativa das cercárias (fase de invasão) através da pele ou das mucosas mesmo íntegras, sendo bem estudada em animais de experimentação. Quando o organismo entra em contato com águas poluidas por cercárias, estas se fixam à pele por meio das ventosas oral e ventral e pela ação dos movimentos vibratórios da cauda e da secreção lítica das glândulas anteriores, iniciando a penetração. No ato de penetração, que dura de 2 a 15 minutos, as cercárias esvaziam o conteúdo de suas glândulas, liberando enzimas proteolíticas, elastolíticas, estereoliticas, lipases e mucopolissacaridases 2325 . Ao penetrar, perdem a cauda bifurcada e se transformam em esquistossômulos, que permanecem na pele por 48 a 72 horas $^{76}$.

Trabalho dos Departamentos de Anatomia Patológica e Medicina Legal e de Clinica Medica da Universidade Federal de Minas Gerais e de Biologia (ICEB) da Universidade Federal de Ouro Preto, realizado com auxilio do CNPq e FINEP

Endereço para correspondência: Pedro Raso - Faculdade de Medicina da UFMG. Av. Alfredo Balena, 190-30000, Belo Horizonte - MG.

Recebido para publicação em 4/3/85.
No homem, biópsias de pele, 2 horas e meia após a exposição, mostram parasitas dentro de túneis escavados pelas cercárias na epiderme e um infiltrado inflamatório agudo, discreto, de neutrofilos e eosinófilos dentro dos túneis e nas regiões subjacentes do derma 677 . Biópsias realizadas 50 horas depois demonstram, ainda, a presença de túneis, porém não se encontram mais cercárias na pele.

Nakamoto ${ }^{20}$ expôs sua própria pele a cercárias de S. japonicum; estas provocaram prurido e a biópsia local, feita duas horas depois, mostrou cercárias na epiderme, sem nenhuma reação. Experiência semelhante, in anima nobile, foi feita por Vogel (1932), que aplicou 9 cercárias de $S$. mansoni em um indivíduo infectado antes, propositadamente, com cercárias de Trichobillarzia ocellata. A biópsia, 2 horas e meia depois, mostrou cercárias envolvidas por neutrófilos e eosinófilos na parte inferior da epiderme.

Em camundongos infectados com grande número de cercárias $(500,1000,2000)$ desenvolve-se reação inflamatória, que sugere mais uma resposta mediada por anticorpos do que por hipersensibilidade retardada ${ }^{38}$. A inflamação surge principalmente nos túneis de penetração e 6 a 8 horas depois da exposição mais de $90 \%$ do exsudato são granulócitos; os linfócitos e monócitos são poucos e os plasmócitos extremamente raros. Nos animais previamente imunizados, a concentração de eosinófilos é 9 vezes maior do que nos não imunes. Por volta de $24-48 \mathrm{~h}$ o infiltrado é maior, depois diminui.

Em conseqüência da penetração, metamorfose e destruição das cercárias, tanto na pele de animais imunes como não imunes, há liberação de uma multiplicidade de produtos enzimáticos e antigênicos (cauda de cercárias, glicoproteinas do glicocálice, secreção das glândulas pré e pós-acetabulares, antigenos somáticos, etc.). Alguns destes produtos, como as proteases, p.ex., podem atuar diretamente sobre os mastócitos, provocando a desgranulação e a liberação de histamina e aminas vasoativas. Por outro lado, esquistossômulos recém-transformados em presença de soro normal ativam o complemento por via alternada. A ativação do complemento seria responsável:

1. pela morte dos esquistossômulos jovens observada in vitro;

2. pela desgranulação dos mastócitos com liberação de histamina, iniciando, assim, o fenômeno 
vascular da inflamação (hiperemia e aumento da permeabilidade vascular);

3. pela liberação de fatores quimiotáticos para eosinófilos (que é potenciada pela presença de anticorpos);

4. pela aderência do eosinófilo à superficie do esquistossômulo, através da interação $\mathrm{C} 3-\mathrm{C} 362$ ou através de anticorpos da classe $\mathrm{IgG}^{8}$ pela interação $\mathrm{Fc}-\mathrm{Fc}^{41}{ }^{79}$. A aderência do eosinófilo ao esquistossômulo e sua destruição sucessiva, anticorpo dependente e complemento dependente, é mais rápida e eficiente quando a adesão é feita através de receptores C3. O eosinófilo, apesar de conter menos receptores $\mathrm{Fc}(\mathrm{FcR})$ para se unir à IgG existente na superfície do esquistossômulo, fixa-se muito mais firmemente do que o neutrófilo, lesando e matando mais o parasito do que o neutrófilo. A lesão do parasito é atribuida, pelo menos em parte, a uma proteína básica principal 78 . $\mathrm{O}$ eosinófilo desgranulado degenera, morre e é fagocitado pelos macrófagos e o desnudamento da membrana do parasito leva-o à morte.

A aderência do neutrófilo é maior quando o soro contém complemento. A aderência varia. Ocorre em poucos pontos e somente $5 \%$ deles conseguem descarregar os seus grânulos na superfície do parasito. $\mathrm{O}$ macrófago pode matar o esquistossômulo, na ausência de anticorpo e de complemento ${ }^{19}$. Sua aderência está ligada à presença de IgE, na forma de imunocomplexos. Experiências demonstram que macrófagos sensibilizados por complexos de IgE aderem à superficie, liberam enzimas lisossômicas e emitem microvilos que penetram no corpo do parasito, destruindo-o.

Ainda não foi descrita atividade citotóxica dos linfócitos, mas sabe-se que eles estimulam a migração de eosinófilos e de células mononucleares, através de linfocinas 74 .

Apesar do grande número de pacientes observados, desconhece-se quais são as alterações histológicas da pele na FAT. É possivel que lesões e mecanismos semelhantes aos observados em animais e in vitro possam ocorrer tambem no homem.

As manifestaçôes cutâneas na FAT são variáveis. A maioria apresenta erupção urticariforme e sensação de prurido nas regiões corpóreas banhadas, de tolerável a inquietante, muitas vezes de duração efêmera, que se inicia logo após ter sido enxugada a pele, cessando espontaneamente ou através da fricção de álcool ou querosene, nas primeiras 24 horas. As manifestações ditas insuportáveis são acompanhadas de pequenas pápulas semelhantes à picada de inseto, seguida de eritema. flictenas, dor e prurido exacerbado. Este quadro pode perdurar até 7 a 10 dias e surge tanto em primo como reinfectados 53 . A intensidade da reação cutânea varia de individuo para individuo e parece ser mediada pela reação humoral.
Mecanismos de escape dos esquistossômulos. As experiências em animais, sobretudo no camundongo, com suporte de estudos in vitro, mostram que os esquistossômulos que conseguiram escapar à reação imune ao nivel da pele, ganham a circulação sangüinea e/ou linfática e migram em direção do pulmão, onde são encontrados a partir de 22 horas. Nos animais virgens, depois de vencida a barreira da pele, não há perda significativa de esquistossômulos. Nos animais previamente infectados 15 a 16 semanas antes da reinfecção, surgem mais duas fases de atrito: no pulmão, onde são recuperados $30 \%$ menos de esquistossômulos do que nos camundongos nãoimunes, e no figado (14 a 21 dias) onde há perda de $50 \%$ da população reinfectante. Este fato indica que o hospedeiro é capaz de resistir à reinfecção e manter vivo, nos vasos sangüineos, por um longo periodo de tempo (20-25 anos), os vermes adultos provenientes da infecção anterior.

A habilidade de escapar à resposta imune do hospedeiro desenvolve-se logo após a penetração da cercária na pele. Esquistossômulos que permanecem 1 a 4 dias na pele perdem a susceptibilidade a anticorpos letais e a anticorpos inibidores do crescimento ${ }^{1}{ }^{1}$; alem disso, o eosinófilo não adere ao parasito de 4 dias recuperado do pulmão, através de receptores de complemento ou de anticorpos.

Portanto, as experiências demonstram que a resposta imune do hospedeiro é capaz de destruir uma parte da população infectante na pele, logo após a transformação das cercárias em esquistossômulos, mas, uma percentagem de parasitos, por mecanismos não totalmente esclarecidos e contraditórios, escapa à destruição e segue o seu ciclo. Duas teorias tentam explicar o escape à resposta imune do hospedeiro: a de ganho (teoria do mascaramento) e a de perda. Segundo a primeira teoria, durante o desenvolvimento do esquistossômulo até tornar-se adulto, ele incorporaria à sua membrana antígenos do hospedeiro (glicolipides, glicoproteinas, imunoglobinas, triglicérides e colesterol), que, não sendo reconhecidos como estranhos, o protegeriam contra a destruição. Os esquistossômulos jovens, recém-transformados de cercárias e sem tempo de adquirir estes antigenos, tornam-se vulneráveis ao ataque imune do hospedeiro e são destruidos.

Em contrapartida, outros experimentos 71 empregando anticorpos mostram que a ligação do anticorpo antiparasito à superficie do esquistossômulo da pele, recém-transformado, perde-se espontaneamente no periodo de 18 horas. Este resultado indica mais perda de antigeno por parte do parasito, à medida que se desenvolve, do que mascaramento da superficie por parte do hospedeiro.

Vasos linfáticos. Linfonodos. Pulmóes. Os parasitos que escaparam à resposta imune ao nivel da pele, e que seguiram através dos linfáticos que drenam 
a porta de entrada, podem induzir, no seu trajeto, obstrução, ruptura, linforragia e infiltrado eosinofilico fugaz e, nos linfonodos aferentes, infiltrado de eosinófilos e de macrófagos nos seios capsulares. Os que seguem a via sangüinea provavelmente, provocam reações semelhantes nos capilares e vênulas 34 .

Independentemente da via seguida, os esquistossômulos ganham o coração direito e dai são levados aos pulmões, onde são encontrados a partir de 22 horas após a penetração, atingindo nível máximo de concentração no $6{ }^{\circ}$ dia. Um retardo na migração pelepulmão é comum nos animais imunes. Os camundongos imunizados permitem a chegada de 25 a $30 \%$ e os não-imune de 35 a $40 \%$ da população infectante nos pulmões 4647 . A permanência nesse órgão é de 3 a 21 dias $70 \mathrm{e}$, durante este período, o parasito parece não se desenvolver, mantendo as mesmas características do esquistossômulo da pele. Entretanto alguns admitem que, à medida que amadurecem, aumenta o número de particulas intramembranosas na face externa do tegumento.

Até o momento, não se conhecem as alterações anatômicas provocadas pelos esquistossômulos no pulmão humano. $O$ que se sabe deriva de dados experimentais e de algumas observações clínicas.

Em animais de experimentação, as lesões são inconstantes e geralmente discretas. Consistem, sobretudo, em arteriolite, arterite, endarterite e focos de necrose 42434469 . Podem ocorrer congestão e ruptura de capilares alveolares, com produção de pequenos focos de hemorragia dentro dos alvéolos 80 . A reação em torno dos esquistossômulos é focal e minima, com maior número de eosinófilos nos animais imunes 39 .

$\hat{\mathrm{E}}$ provável que no homem ocorram lesōes semelhantes, que, na maioria das vezes devem ser discretas, focais e fugazes, em conseqüência, provavelmente, da destruição de esquistossômulos no pulmão ${ }^{63}$ o que alguns admitem decorrer de uma reação alérgica à migração de larvas.

Nesse período podem ocorrer, no homem, sintomas e sinais respiratórios de duração efêmera ou mais persistente, como tosse seca ou produtiva, dispnéia e expectoração mucosa, estado gripal, acompanhados ou não de sintomas clínicos gerais, como sensação de fadiga, tonturas, diarréia muco sangüínolenta de média intensidade, linfadenomegalia difusa, esplenomegalia, comportando-se eles como pródomos de um acometimento toxi-infeccioso futuro ${ }^{54}$. A radiografia do tórax pode mostrar hilos densos e trama vascular espessada.

Figado. Depois da permanência, por um periodo variável, nos pulmões, os esquistossômulos chegam ao figado por duas rotas; sangüinea e transtextural (pleura visceral, cavidade pleural, diafragma, cápsula de Glisson ${ }^{70}$ ) e a fase de maturação vai do 8 . ao 26. dia, aproximadamente. Neste periodo, no camundongo, surge reação inflamatória discreta e em focos, em torno de esquistossômulos ou independentemente da sua presença, caracterizada por infiltrado de granulócitos e de células mononucleares e raros eosinófilos e por necrose de hepatócitos isolados. No 21. dia aumenta o número de células mononucleares e no $280^{\circ}$ dia os focos de inflamação intralobular em torno de produtos de desintegração dos parasitos são maiores e contêm principalmente granulócitos neutrófilos e eosinófilos 68 .

Pouco se sabe sobre as lesões hepáticas no homem, neste periodo. A experiência antomopatológica se resume nos achados em très punçõesbiópsias $^{3}$, correspondentes a três pacientes.

As punções realizadas no $20 \circ, 210^{\circ}$ e $22{ }^{\circ}$ dias de evolução mostraram hepatite em pequenos focos sistematizados, não relacionados diretamente com a presença topográfica de esquistossômulos, caracterizada por exsudato de neutrófilos, linfócitos e raros plasmócitos, na intimidade dos lóbulos e nos espaços portais. Os eosinófilos eram excepcionais. Havia necrose por esfacelo ou por coagulação de poucos hepatócitos, perda da basofilia e degeneração hidrópica (células in plant like). Os sinusóides eram estreitados nas áreas de degeneração e dilatados em outras e as células de Küpffer eram hipertróficas.

Coincidindo com a chegada, permanência, crescimento e maturação dos parasitos no fígado, eclode rica sintomatologia clínica 5153 . De fato, nos portadores da FAT, por volta do $150^{\circ}$ ou $160^{\circ}$ dia, em geral no $19 \circ$, quando praticamente não há mais esquistossômulos nos pulmões, surge sintomatologia clínica bem definida muitas vezes explosiva, caracterizada por febre alta $\left(38-39^{\circ} \mathrm{C}\right)$, sudorese intensa, cefaléia, dores musculares generalizadas, linfadenia, hepatesplenomegalia, diarréia mucosanguinolenta com 8 a 10 dejeções diárias, dor abdominal, tosse produtiva, alterações urticariformes da pele (independentes do banho infectante e interpretados como reação de hipersensibilidade de tipo I, mediada por IgE).

As provas de função hepática (cefalina colesterol, timol floculação e turvação, bilirrubinas, proteinas totais e transaminases), corroborando com as alterações histopatológicas, permanecem dentro dos limites da normalidade. Em alguns casos ocorre inversão da relação albumina/globulina.

É razoável admitir-se que esta primeira reação geral, febril e textrina (hepatite, esplenomegalia, etc.) decorra da destruição e desintegração maciça dos esquistossômulos que atuam como agentes flogísticos e antigênicos. É possivel hipotetizar, nesta fase, a formação de imunocomplexos que bloqueariam a imunidade celular. Por outro lado, é possivel que a rápida mudança da superficie do parasito (ganho ou perda de partículas) possa torná-lo susceptivel à ação 
de anticorpos do tipo IgE (que explicaria a asma, urticária e eosinofilia) e IgG (responsável pela febre e leucocitose). Estas hipóteses necessitam de comprovação. $\mathrm{O}$ único meio de torná-las mais claras seria a reprodução da FAT em animais, ainda não conseguida.

Fase postural e pós-postural. É o periodo evolutivo que coincide e sucede à oviposição. Sua duração e manifestações clínicas são extremamente variáveis.

Atingida a maturidade no sistema porta, os vermes adultos, isolados ou acasalados, caminham contra a corrente em direção dos ramos mesentéricos, especialmente da veia mesentérica inferior. Chegando aos vasos da parede intestinal, especialmente da submucosa, a fêmea começa a depositar seus ovos na luz das vênulas. $O$ inicio da postura é variável, podendo ocorrer entre o 27. e o 48. dia de infecção 21266160. Os ovos depositados um a um, em fila indiana, seguem vários caminhos:

1. Uma parte ganha a luz intestinal, sendo eliminada pelas fezes (calcula-se que cada fêmea põe, no hamster, uma média de 300 ovos por dia e que $22 \%$ deles alcançam a luz intestinal e são eliminados ${ }^{49}$ ). Foram invocados vários mecanismos 73 para explicar a saída do ovo da luz vascular: (a) ação mecânica da espicula; (b) ação enzimática do miracídio em desenvolvimento; (c) pressão exercida pelo próprio corpo do verme; (d) pressão exercida pelo bolo fecal sólido; (e) contrações do intestino resultantes dos movimentos peristálticos.

Ao sair dos vasos, os ovos provocam pequenas hemorragias (raramente hemorragias maiores) perivasculares e soluções de continuidade do epitélio, facilmente reparáveis. Quando eliminados em grande quantidade, as lesōes podem ser mais intensas.

2. Parte dos ovos ganha a corrente sanguinea e/ou linfática e é levada a vários órgãos e tecidos. Este fenômeno de embolização é particularmente intenso na FAT.

3. Outros ovos, entretanto, permanecem na parede intestinal, onde provocam a lesão granulomatosa característica.

Coincidindo com a postura dos ovos, surge uma rica sintomatologia clínica 2253 , que simula quadros clínicos diversos, como febre tifóide, enterocolites agudas, bronquites, broncopneumonites, hepatite anictérica, glomerulonefrite, dermatoses alérgicas, doenças viróticas sistêmicas, etc. 2453 . Caracteriza-se, na maioria das vezes, por febre alta $\left(38-39^{\circ} \mathrm{C}\right)$, anárquica (92\%), com calafrios, sudorese, sensação de calor, prostação, diarréia $(96 \%)$, com 10 a 15 dejeções diárias, aquosas e depois muco-sangüinolentas, cólicas abdominais (92\%), tenesmo, borborigmos, enterorragia, às vezes copiosa, náuseas, vômitos (32\%), fraqueza geral (84\%), hepatomegalia (68\%), espleno- megalia (44\%), palidez (60\%) e erupção cutânea urticariforme $(72 \%)$, linfadenomegalia $(32 \%)$. As manifestações pulmonares como tosse seca ou produtiva, roquenha e dispnéia, lembram, pelos aspectos clínicos e radiológicos, a chamada "pneumonia pulmonar infiltrativa" ou, às vezes, a tuberculose pulmonar. Espessamento hilar particularmente do hilo esquerdo, acentuação da estriação pulmonar, tortuosidade e imprecisão dos contornos vasculares, disseminação micronodular, formação de rosário e mais raramente espessamento da cisura hilar, visualizada ao RX. A área cardíaca e a artéria pulmonar são normais mas não raro ocorre retificação e abaulamento do arco médio 5872 . Após tratamento surgem imagens, ora de pneumonite por verme morto, ora como expressão alérgica às drogas ou a produtos de vermes ${ }^{28}$. Em casos raros pode surgir cor pulmonale. Há taquicardia ( $90 \%$ ), hipertensão $(78 \%)$, hiperfonese e desdobramento de P2 ( 8 a 10\%), emagrecimento, mialgia, torpor intenso. Surge leucocitose $(10$ a $25000 / \mathrm{mm}^{3}$ ), eosinofilia em torno de $5000 / \mathrm{mm}^{3}$ e, às vezes, reações leucemóides ${ }^{54}$, sugerindo estado de hipersensibilidade global e textrina; anemia, hiperglobulinemia com aumento da fração gama e alfa $2^{2}$, alterações discretas da floculação e turvação do timol, diminuição dos fatores $\mathrm{V}$ e do complexo VII-X da coagulação.

Bases anatômicas da fase pós-postural da forma aguda. Foram bem estabelecidas, nos quatro casos estudados por Bogliolo (1958), e confirmados nos outros oito casos necropsiados por Raso, entre 65 e 130 dias após a infecção, e no estudo de mais de duas centenas de punçōes biopsias hepática ${ }^{63}$. Basicamente se caracterizam pelos seguintes fatos:

1. Disseminação miliar intensa, maciça, de ovos com formação de granulomas esquistossomóticos no figado, intestino grosso e delgado, peritônio visceral, linfonodos da cavidade abdominal e hilos pulmonares, pulmões, pleura e pâncreas e, com menor freqüência, em outros órgãos.

Lesões pelos ovos. A lesão fundamental na esquistossomose, independentemente da forma anátomo-clínica da doença, é a reação granulomatosa induzida pelos ovos. Na FAT são inúmeros os granulomas na superficie e na intimidade dos órgãos, sobretudo no figado, pulmões e serosa dos intestino grosso e delgado. Apresentam-se sob a forma de minúsculos nódulos brancacentos, do tamanho da cabeça ou da ponta de alfinete, aos milhares, muitas vezes confluentes, conferindo uma cor brancacenta à superfície externa desses órgãos.

A reação granulomatosa que envolve o ovo é uma resposta imune a produtos antigênicos liberados pela secreção do miracídio maduro 29 . O embrião contido dentro do ovo só se torna maduro cerca de 6 dias após a postura do ovo pela fêmea. Nem a casca e 
Revisão. Raso P. Pedroso ERP, Neves J. Patologia da forma aguda, toxêmica, da esquistossomose mansoni. Revista da Sociedade Brasileira de Medicina Tropical 19: 45-55, Jan-Mar, 1986

nem o miracidio isolados provocam granulomas 437 . Do mesmo modo, não provocam reações semelhantes os produtos derivados das cercárias e dos vermes adultos. Dos antigenos solúveis do ovo (SEA), que se difundem através dos poros existentes na casca, pelo menos 6 a 12 são capazes de induzir sintese de anticorpos precipitantes 10 . Os componentes solúveis são principalmente proteínas e glicoproteinas ${ }^{59}$ mas contém, também, lípides ${ }^{75}$. O pico de anticorpos de $S$. mansoni ocorre quando o granuloma atinge o seu tamanho máximo ${ }^{5}$ 14. Pelo método da imunodifusão foram reconhecidos três antigenos: MSA1, MSA2, MSA3 (major serologic antigens). Pelley (1977) admite que o MSA1, uma glicoproteina de PM 100.000 a 130.000 , seja o indutor da reação granulomatosa. Todavia, dada a complexidade dos constituintes antigênicos e não antigênicos do ovo e a capacidade do organismo de responder a estes constituintes, é improvável que o granuloma seja uma resposta apenas a um determinado antigeno.

O material imunogênico liberado do ovo induz a migração e aderência de células mononucleares. Após a aderência, as células mononucleares sofrem transformação blástica e recrutam mais linfócitos e macrófagos. Estes, por sua vez, secretam substâncias ativas que atraem outras células para o foco (fibroblastos, imunoblastos, eosinófilos, neutrófilos, macrófagos epitelióides, plasmócitos). O máximo da resposta celular in vitro é de 6 a 9 dias e in vivo de 8 a 16 dias. Há diferenças na composiçào celular dos granulomas do figado, cólon e íleo de camundongo. Os do fígado contèm maior número de linfócitos $\mathrm{T}$ e $\mathrm{B}$, eosinófilos $\mathrm{e}$ mastócitos; os do ileo e do cólon principalmente macrófago, com menos células adicionais. As diferenças de tamanho dos granulomas em vários setores do organismo são governadas parcialmente pelos linfócitos $\mathrm{T}$.

A disseminação de ovos e a reação granulomatosa em torno deles no fígado e em outros órgãos na FAT difere da encontrada em outras formas de esquistossomose pelas seguintes características: (a) Contemporaneidade dos granulomas, isto é, todos na mesma fase reacional. Em punçōes biópsias seriadas do figado os granulomas apresentam 4 caracteristicas fundamentais: necrótico-exsudativo, exsudativos, produtivos e em fase de cura por fibrose ${ }^{64}$. Os necroticoexsudativos sobretudo até o 70-78. dia, às vezes até 110 dias $^{63}$, são os mais comuns; (b) extensão incomum da zona central de necrose, formando os granulomas inusitadamente volumosos (granulomas hiperérgicos), notadamente no fígado, intestino, peritônio visceral, pâncreas e pulmões; (c) distribuição dos ovos e granulomas no figado irregular, situando-se tanto na intimidade dos lóbulos como nos espaços portais.
2. É constante, na FAT, a enterocolite ulcerativa aguda superficial, por vezes levemente hemorrágica, disseminada ao longo de todo o intestino delgado e grosso. As úlceras em geral são minúsculas, punctiformes, de 1 a $1,5 \mathrm{~mm}$ de diâmetro, com bordas planas e regulares. Outras são maiores, irregulares, lembrando escoriações. Raramente são extensas, profundas, com perfuração e peritonite purulenta consecutiva 66 . É constante a enterocolite catarral aguda, mais intensa no delgado, caracterizada por congestão, edema e descamação do epitélio, acompanhado de infiltrado inflamatório, quase sempre intenso, difuso ou focal, de granulócitos neutrófilos e eosinófilos, linfócitos e plasmócitos, em proporções variáveis, na lâmina própria e na submucosa, independentemente da lesão granulomatosa.

Estas lesões, responsáveis pela rica sintomatologia intestinal (diarréia aquosa ou mucosanguinolenta, dor abdominal, tenesmo, borborigmos, náuseas, vômitos e, às vezes, enterorragia copiosa), dificilmente poderiam ser atribuidas apenas à ação local dos ovos e dos granulomas. À luz dos conhecimentos atuais, não se pode excluir a ação de imunocomplexos, cuja concentração é sempre mais alta nas fases agudas do que nas crônicas da doença. De fato, o $\mathrm{C}_{1} \mathrm{q} \mathrm{BA}$ atinge o ponto máximo na 10 a semana após a infecção, é proporcional ao número de ovos nas fezes, e reflete a atividade da doença 30 . Os ovos são capazes de liberar fatores tóxicos e a toxidade pode ser controlada por mecanismos efetores imunológicos, especialmente humorais 918 . Aliás, no inicio da oviposição elevam-se concentrações das imunoglobulinas $\operatorname{IgE}, \operatorname{IgG}, \operatorname{IgM}$ e IgA.

A endoscopia nesta fase mostra mucosa edemaciada, hiperêmica, com ponteado hemorrágico e úlceras superficiais. O oograma é pobre na fase inicial e rico no periodo de estado ${ }^{15}$.

Até o momento não se sabe como evoluem as lesōes intestinais e quais as suas relações com as formas intestinais crônicas, como a ulcerosa, poliposa e pseudotumoral. É possivel, a julgar pelos pacientes que superam esta fase, que possa haver cura da inflamação sem provocar grandes transtornos funcionais.

3. Outro órgão constantemente acometido na $F A T$ é o figado. A lesão fundamental consiste na disseminação miliar intensa de ovos, com formação de numerosos granulomas espalhados na superficie do órgão e localizados indistintamente no parênquima $\mathrm{e}$ nos espaços portais. Coexiste sempre reação inflamatória focal, intra e extralobular, independente da reação granulomatosa. As lesões por verme são ocasionais. Pigmento esquistossomótico é identificado nas células de Küpffer e nos macrófagos dos espaços porta. 
Revisão. Raso P, Pedroso ERP, Neves J. Patologia da forma aguda, toxêmica, da esquistossomose mansoni. Revista da Sociedade Brasileira de Medicina Tropical 19: 45-55, Jan-Mar, 1986

As alterações dos hepatócitos, mesmo nas formas mais graves que evoluiram para o obito, secundárias à inflamação e ao estado toxêmico, em geral são pouco pronunciadas e nunca atingem a gravidade vista em outras hepatopatias caracterizadas pela agressão direta ao hepatócito.

À microscopia óptica se caracterizam, principalmente pela perda da basofilia, degeneração hidrópica ou vacuolar, células in plant like e, mais raramente, por necrose por esfacelo e hialina de hepatócitos isolados. A microscopia eletrônica mostra: (1) alargamento dos espaços intercelulares por edema; (2) alargamento difuso do REL e RER, às vezes pronunciado; (3) tumefação da matriz e perda das cristas mitocondriais; (4) inclusões paracristalinas nas mitocôndrias; (5) descoplamento e diminuição dos ribossomas; (6) aumento apreciável dos grânulos de glicogênio, que, juntamente com a tumefação das mitocôndrias e redução dos ribossomas, explica o aspecto claro do hepatócito visto ao MO; (7) raras e discretas alterações da membrana nuclear; (8) particulas osmiofilicas. finamente granulosas, uniformes, isoladas e agrupadas, interpretadas como pigmento férrico e corpos residuais, no citoplasma das celulas de Küpffer e hipertrofia e hiperplasia dessas células; (9) luz dos sinusóides dilatadas em certas áreas e estreitadas em outras, sendo nas porções dilatadas freqüente o encontro de hemácias, granulócitos neutrófilos, linfócitos e plasmócitos.

Portanto, as alterações dos hepatócitos fora da região onde existe granuloma são discretas e inespecificas e condizentes com a discreção das alteraçōes funcionais do figado na FAT (diminuição das proteinas totais e da albumina, mais por perda intestinal, inversão da relação albumina/globulina, alteração discreta da floculação e turvação do timol, aumento das globulinas gama e alfa 2 , diminuição dos fatores $\mathrm{V}$ e do complexo VII-X da coagulação). A ictericia observada em alguns casos não é do tipo hepatocelular e provavelmente deriva da hemorragia intestinal, como em um caso onde havia $1000 \mathrm{ml}$ de sangue na luz do cólon e do reto.

4. A terceira sede de lesões importantes é representada pelo pulmão. A lesão fundamental consiste, igualmente, na disseminação miliar intensa de ovos e na formação de granulomas na mesma fase e com as mesmas caracteristicas dos granulomas hepáticos. Não há sede de predileção, mas ocorrem com maior intensidade nas regiōes subpleurais. Prevalecem nos pequenos ramos arteriais e em torno deles. As lesões arteriais são de pequena monta e caracterizam-se por pequenas áreas de necrose de parte do arco vascular, arterite e arteriolite discretas ${ }^{63}$. Raramente as lesōes são mais graves. A pneumonite por verme morto não é comum. Além das lesões provocadas diretamente pelos ovos, è freqüente a congestão, o edema e a broncopneumonite. No camundongo, na fase aguda, pode ocorrer deposição de imunocomplexos nos septos e pneumonite intersticial 2734 .

As lesões anatômicas explicam o aparecimento precoce de alteraçôes radiológicas (espessamento hilar, especialmente do hilo esquerdo, acentuação da estriação pulmonar, tortuosidade e imprecisão dos contornos vasculares, micronódulos disseminados, que podem simular a tuberculose miliar, presença de rosário e, mais raramente, espessamento da cisura hilar e áreas de menor transparência). Outras alterações radiológicas podem ocorrer principalmente após tratamento, como a da pneumonite por verme morto. O cor pulmonale, relacionado à primo infecção maciça ou a superinfecções repetidas, è raro ${ }^{73}$.

5. O quadro anatômico da $F A T^{1}$ completa-se com o encontro de ovos e granulomas, na mesma fase evolutiva e com as mesmas caracteristicas descritas, em outros órgàos. como pâncreas, linfonodos, testículos, medula espinhal, etc. É constante o "tumor infectuoso agudo" do baço, com congestão intensa, espessamento dos cordões de Billroth provocado pela hiperplasia dos histiócitos e a infiltração difusa de eosinófilos. As lesões dos demais órgãos são inespecificas, não permitindo o diagnóstico da FAT ${ }^{1}$.

Evolução da FAT. Os casos até então registrados na literatura mostram que a FAT pode evoluir para a: (1) cura espontânea; (2) cura pós-tratamento; (3) forma hepatesplênica; (4) cor pulmonale; (5) outras formas crônicas; (6) obito.

(1) A duração da FAT é bastante variável e os limites entre ela e a fase crônica são imprecisos. $\mathrm{Na}$ maioria dos casos não tratados especificamente para a esquistossomose nesta forma, a sintomatologia clinica permaneceu por 90 a 120 dias após a infecção. Este pode ser considerado o periodo critico, pois, a partir daí há melhora progressiva dos sintomas e sinais, com aparente cura da doença. Às vezes os sintomas começam a desaparecer antes de 90 dias; em outros casos persistem além dos 120 dias. Pelas características dos granulomas hepáticos não foi possivel distingui-la da forma crônica a partir de 150 dias de evolução. Três pacientes reexaminados 13 anos após o episódio agudo não mostraram mais vestígios da doença ${ }^{66}$. O quadro anatômico da forma curada mostra disseminaçāo intensa de milhares de ovos e granulomas cicatrizados nas mesmas sedes e com idêntica distribuição da $\mathrm{FAT}^{1}$.

(2) Evolução para a cura pós-tratamento especifico. Como a infecção, na maioria dos casos, tende a evoluir espontaneamente, com mais razão ela ocorre nos casos especificamente tratados. Os corticóides melhoram os sintomas clinicos e sua retirada é seguida de recrudescimento dos sintomas 65 . 
(3) Evolução para a forma hepatesplênica. Embora possivel, parece ser rara a julgar pelos relatos da literatura 16454851 .

(4) Evolução para o cor pulmonale. São pou$\cos$ os casos descritos na literatura ${ }^{73}$. Um deles surgiu em uma criança de 10 anos, portadora de sintomas da FAT de longa duração, com vários surtos de diarréia e de outros sintomas que cederam apenas 20 meses depois da infecção. $O$ outro caso era de uma menina de 7 anos, com vários contatos com águas desde os 4 anos de idade. Além das alterações freqüentemente encontradas nos $\mathrm{RX}$ dos pulmões na forma toxêmica, havia dilatação precoce da artéria pulmonar, retificação do arco média, aumento da área cardiaca e hiperfonese de $\mathrm{P} 2$.

(5) Evolução para outras formas crônicas. Não há, ao que saibamos, registros na literatura. Todavia, na nossa opinião, não se pode descartar a possibilidade da forma pseudotumoral ter o seu determinismo na FAT.

(6) Evolução para óbito. Até o momento, dos casos observados em Minas Gerais foram autopsiados 12 (4 por Bogliolo e 8 por Raso). Os primeiros foram tratados pelo antimônio; os últimos receberam, apenas, tratamento paliativo.

(7) Conseqüencias e complicações. As mais comuns são:

- Abdômen agudo clínico, observado principalmente na primeira semana após a postura, caracterizado por defesa abdominal (abdômen tenso e doloroso), acompanhada de leucocitose e eosinofilia. Ocorre em aproximadamente $10 \%$ dos casos, principalmente em pacientes nāo tratados especificamente.

- Abdômen agudo cirúrgico. Alguns pacientes com abdomen agudo clinico evoluiram para o quadro de abdômen agudo cirúrgico de uma hora para outra (abdômen em tábua, mais doloroso, leucocitose, desvio para esquerda e queda dos eosinófilos). As cirurgias realizadas não revelaram perfuração. Não se sabe se houve perfuração com tamponamento imediato da lesão.

- Massa abdominal. É relativamente freqüente (cerca de $25 \%$ dos casos). Localiza-se predominantemente na fossa iliaca e por vezes sofre regressão espontânea alguns meses depois.

- Diarréia crônica e desnutrição crônica pronunciada. Não é rara, após desaparecimento dos sintomas toxêmicos.

- Enterorragias e choque. Não é freqüente.

- Complicaçóes neurológicas. Estão relatadas várias formas de manifestações neurológicas, algumas delas ligadas à deposição de ovos no sistema nervoso no decurso da FAT. Entre elas destacam-se a mielite transversa com paraplegia, polirradiculite e sindrome semelhante a Guillain-Barré 46.

\section{PATOGENIA DA FAT}

Pouco se sabe a respeito da etiologia da forma aguda toxêmica. A rica sintomatologia clínica observada duas a três semanas após a infecção (febre, urticária, hepatesplenomegalia, dor abdominal, náusea, diarréia e eosinofilia, entre outros eventos), portanto antes da oviposição, indica claramente não ser o ovo o responsável pelas manifestações clinicas. Pelo contrário coincide com a fase de maturação dos esquistossômulos e da migração pelo pulmão e figado. Como na febre de Katayama, os sintomas são comparáveis aos observados na doença do soro ou doença por imunocomplexos. Von Pirquet e Schick (in Kohler, 1978) ao decreverem a doença do soro no homem, em 1905, foram os primeiros a atribuir papel patogênico dos complexos antigeno-anticorpo ou imunocomplexos (IC). Admitiram que a integração de antígenos protéicos estranhos (exógenos), no caso soro eqüino anti-rábico, com anticorpos especificos seria a responsável pelas manifestações da doença do soro-exantema, febre, linfadenopatia, envolvimento articular, glomerulonefrite, neurite, pneumonite. Sintomatologia muito semelhante foi obtida em coelhos injetados por via endovenosa com maiores quantidades de soro (albumina bovina, $250 \mathrm{mg} / \mathrm{kg}$ de peso). Dixon et al (1958) observaram na fase 3 , de eliminação imunológica, ou seja, entre o $8^{\circ}$ e $12{ }^{\circ}$ dias, coincidindo como desenvolvimento de arterite disseminada e glomerulonefrite, a formação de complexos soro-albumina bovina, anti-soro-albumina-bovina. Antigeno, anticorpo e o componente $\mathrm{C} 3$ do complemento foram identificadas por imunofluorescência nos locais de lesão textural. Mas, nem todos os animais reagiram da mesma forma, indicando haver caracteristicas especificas do hospedeiro nesta resposta. Como esperado, a doença do soro aguda é autolimitada; cessa a formação de IC, assim que o antigeno (iniciante ou desencadeante) seja eliminado. A doença do soro crônica pode ser induzida injetando-se antígeno repetidamente, em quantidades superiores aos niveis de anticorpo circulante, de modo a formar complexos solúveis, com excesso de antígeno. Na FAT poderia ocorrer o mesmo. Poder-se-ia admitir que numa parcela de pacientes infectados numa primeira fase haveria grande destruição de esquistossômulos no pulmão e no fígado, com concentração elevada de antigenos no sistema vascular e, conseqüentemente, maior formação de anticorpos. O excesso de anticorpos e antígenos na circulação formariam complexos solúveis maiores, capazes de ativar o complemento, e não elimináveis facilmente pelos polimorfonucleares e pelo sistema fagocitico mononuclear antes de se localizarem nos vasos e tecido. $\mathrm{O}$ primeiro anticorpo a aparecer é dirigido contra cercárias ${ }^{40}$ e formados principalmente de $\operatorname{IgM}$ e IgG especificos para o intestino das 
cercárias. Estes anticorpos estão muito mais elevados na FAT do que nos indivíduos com as formas crônicas ${ }^{50}$ e atingem niveis mais elevados no início da postura dos ovos. Dentre as imunoglobulinas a IgE parece ter um papel preponderante. A IgE especifica se encontra aumentada no soro de pacientes com doença do soro aguda 12 e em infecções parasitárias 56 . Os IC solúveis só causam dano textural se existe concomitantemente aumento da permeabilidade vascular $^{13}$ e este é desencadeado, no coelho, pela $\mathrm{IgE}^{1}$. Basófilos humanos sensibilizados com anticorpos IgE e expostos ao antigeno liberam um fator de ativação plaquetária (FAP), histamina, fator quimiotático para eosinófilo (FQE-A), substância de reação lenta (SRL-A), calicreina e outros. Os medidadores liberados sobretudo a histamina e a calicreina, aumentam a permeabilidade vascular, importante fator para a deposição de IC nos tecidos ${ }^{32}$. Por outro lado, os IC circulantes contendo uma molécula de IgM ou duas de IgG, adjacentes, interagem com o componente $\mathrm{C} 1$, iniciando a seqüência clássica da ativação do complemento. O C3 é essencial na liberação dos mediadores quimicos da inflamação. Os fragmentos $\mathrm{C} 3 \mathrm{e}$ C5a (anafilatoxinas) liberam mediadores vasoativos dos mastócitos, aumentando a permeabilidade vascular: eles e o complexo C567 têm função quimiotática para neutrófilos. Além dos monócitos, os neutrófilos, eosinófilos e linfócitos $\mathrm{B}$ possuem receptores para $\mathrm{C} 3 \mathrm{~b}$ que interagem com os complexos $\mathrm{Ag}, \mathrm{Ac}-\mathrm{C} 3 \mathrm{~b}$. Esta ligação, denominada imunoaderência é um dos mecanismos de captação e posterior degradação do IC pelos fagócitos. Além da agressão direta causada pelos componentes C6789 a exsudação local de neutrófilos e eosinófilos participa da reação textural. Os complexos $\mathrm{Ag}-\mathrm{Ac}-\mathrm{C} 3 \mathrm{~b}$, bem como componentes, do próprio macrófago exercendo a fagocitose podem, por exemplo, provocar lesões necróticas e fibrinosas em arteriolas e vênulas, nos capilares glomerulares, etc. A eosinofilia periférica e textural comum nas infecções parasitárias atinge, nesta fase, números elevados, em parte também em conseqüência do estado de hipersensibilidade com IgE circulante elevado. Seu papel já foi analisado. $\mathrm{Na}$ fase pré-postural estão presentes as condições necessárias para o aparecimento de lesões por IC: elaboração continua de antigenos parasitários potentes, produção concomitante de anticorpos pelo hospedeiro e liberação acelerada, em caráter explosivo, quando se institui tratamentos esquistossomicidas 27 . Como na doença do soro, a julgar pela sintomatologia clínica, há um momento em que cessa ou diminui a formação de IC, com eliminação do antígeno desencadeante provindo dos esquistossómulos. Parece que o verme maduro tem pouca participação no processo. De fato, a experiência mostra que a FAT após esta fase de explosão (2a ou 3a semana), passa por um periodo de latência, com melhora do quadro clínico. Por volta do 35 \% ao $40 \%$ dia, aproximadamente, coincidindo com a postura dos ovos, recrudessem os sintomas clínicos. Não há dúvida de que nesta fase, surge uma nova e importante fonte antigênica, representada não mais pelos antigenos dos esquistossômulos, mas dos milhares de ovos que carreados pela circulação se instalam em grande número de órgãos e tecidos do organismo (intestino, figado, peritônio, pulmão, pâncreas, etc.). A partir deste momento é possível compará-la com a doença do soro crônica determinada pela eliminação repetida de antígenos em quantidades superiores aos niveis de anticorpos circulantes, de modo a formar complexos solúveis com excesso de antígenos. Aliás, no início da oviposição elevam-se as concentrações de imunoglobulinas especialmente IgE, $\operatorname{IgG}$ e $\operatorname{IgM}^{31}$ e às vezes $\operatorname{IgA}$. A suposição de circulação prévia de IC é corroborada pelo encontro, na fase crônica da doença, de depósitos granulosos nos glomérulos contendo IgG, IgM, C3, o encontro de antígenos esquistossomóticos circulantes e a presença de anticorpos contra alguns desses antigenos. Os IC encontrados na esquistossomose são de peso molecular variável (de milhares a milhões de daltons) e possuem determinantes antigênicos múltiplos. Cerca de $5 \%$ do aumento total da fração globulinica sérica se devem a anticorpos do $S$. mansoni. Cremos, portanto, que na eclosão da FAT a produção de anticorpo parece ser um fator crucial, pois somente individuos com resposta hiperativa estão sujeitos a ter suas manifestações. A partir do momento da deposição de ovos nos tecidos surge a reação mediada pelas células, com a finalidade de circunscrever a reação inflamatória.

\section{REFERÊNCIAS BIBLIOGRÁFICAS}

1. Benveniste J, Henson PM, Cochrane CG. Leucocytedependent histamine release from rabbit platelets: The role of $\operatorname{IgE}$, basophils and a platelet activating factor. Journal of Experimental Medicine 136: 1356-1377, 1972.

2. Bogliolo L. Esquistossomose mansoni. Patologia. Revista Brasileira de Malariologia e Doenças Tropicais 11: 359-424, 1959.

3. Bogliolo L, Neves J. Ocorrência de hepatite na forma aguda ou toxêmica da esquistossomose mansoni, antes da maturação dos vermes e da postura dos ovos com algumas considerações sobre a forma aguda ou toxêmica da esquistossomose. Anais da Faculdade de Medicina da Universidade de Minas Gerais 22: 47-74, 1965.

4. Boros DL, Warren KS. Delayed hypersensitivity-type granuloma formation and dermal reaction induced and elicited by a soluble factor isolated from $S$. mansoni eggs. Journal of Experimental Medicine 132: 488-507, 1970.

5. Boros DL, Pelley RP, Warren KS. Spontaneous modulation of granulomatous hypersensitivity in schistoso- 
miasis mansoni. Journal of Immunology 114: 1437$1441,1975$.

6. Brackett S. Pathology of schistosomose dermatitis. Archives of Dermatology and Syphilology 42: 410-418, 1940.

7. Brumpt E. Oviposition of the schistosomes. Annales de Pathologie 3-4: 263-297, 1930.

8. Butterworth AE. The eosinophil and its role in immunity to helminth infection. Current Topics in Microbiology and Immunology 11: 127-168, 1977.

9. Byran JE, Doenhoff MJ, Mussallam R, Brink LH, Lichtenberg F. von. Schistosoma mansoni: infections in T-cell-deprived mice, and the ameliorating effect of administering homologous chronic infection serum. II. Pathology. American Journal of Tropical Medicine and Hygiene 28: 274-285, 1979.

10. Carter CE, Colley DG. Partial purification and characterization of $S$. mansoni soluble eggs antigen with Con A-Speharose chromatography. Journal of Immunology 122: 2204-2209, 1979.

11. Clegg JA, Smithers SR. The effect of immune Rhesus monkey serum on schistosomula of $S$. mansoni during cultivation in vitro. International Journal of Parasitology 2: 79-98, 1972.

12. Cochrane CG, Dixon FJ. Immunocomplex injury. In: Samter $M$ (ed) Immunological diseases, $3^{\text {th }}$ edition, Little, Brown, p. 210-229, 1978.

13. Cochrane CG, Koffler D. Immune complex disease in experimental animals and man. Advances in Immunology 16: 185-197, 1973.

14. Colley DG. Immune responses to a soluble schistosome egg antigen preparation during chronic primary infection with $S$. mansoni. Journal of Immunology 115: 150-156, 1975.

15. Cunha AS da, Cançado JR. Tratamento clínico. In: Esquistossomose mansoni, Savier. Editora da Universidade de Sāo Paulo, São Paulo, SP, 1970.

16. Dew HR. Observations on the pathology of schistosomiasis, $S$. haematobium and $S$. mansoni, in the human subject. Journal of Pathology and Bacteriology 26: 27-39, 1923.

17. Dixon FJ, Vasquez JJ, Weigle WO, Cokrane CG. Pathogenesis of serum sickness. Archives of Pathology 65: 18-28, 1958.

18. Dunne DW, Lucas S, Bickle Q, Pearson S, Madgwick L, Bain J. Doenhoff MJ. Identification and partial purification of an antigen (omega I) from $S$. mansoni eggs wich is putatively hepatotoxic in T-cell deprived mice. Transactions of Royal of Society of Tropical Medicine and Hygiene 75: 54-71, 1981.

19. Ellner JJ, Mahamound AA. Killing of schistosomula of Schistosoma mansoni by normal human monocytes. Journal of Immunology 123: 949-951, 1979.

20. Faust EC, Meleney HE. Studies on schistosomiasis japonica (with a supplement on the molluscan of the human blood fluke in China and Japan, and especies liable to be confused with them by $N$. Annandale). American Journal of Hygiene Monography Series 3: 1339, 1929.

21. Faust EC, Jones CA, Hoffmana WA. Studies on schistosomiasis mansoni in Puerto Rico. III- Biological studies. 2- The mamalian phase of the lifecycle. Puerto Rico Journal of Public Health and Tropical Medicine 10: 133-196, 1934.

22. Ferreira $H$, Oliveira CA, Bittencourt D, Katz N, Carneiro LFC, Grinbaum E, Veloso C, Dias RP, Alvarenga RJ, Dias CB. A fase aguda da esquistossomose mansoni. Considerações sobre 25 casos observados em Belo Horizonte. Jornal Brasileiro de Medicina 11: 54-67, 1966.

23. Gazinelle G, Pellegrino J. Elastolytic activity of $S$. mansoni cercariae extract. Journal of Parasitology 50: 591-592, 1964.

24. Gelfand M. Pulmonary schistosomiasis in the early "Katayama" phase of the disease. Journal of Tropical Medicine and Hygiene 69: 143-144, 1966.

25. Gilbert B, Da Rosa M. Borojevic R, Pellegrino J. $S$. mansoni: in vitro transformation of cercariae into schistosomula. Parasitology 64: 333-339, 1972.

26. Girges R. Schistosomiasis (Bilharzioses). John Bale Sons \& Danielson, London, 1934.

27. Greco DB. Infecção por $S$ mansoni e deposição de imune-complexos no pulmão. Estudo experimental. Tese de doutoramento. Universidade Federal de Minas Gerais, Belo Horizonte, MG, 1980.

28. Greco DB, Lambertucci, JR, Pedroso ERP, Coelho PMZ, Starling CEF, Silva FCL, Ferreira MN, Caiaffa WT, Rocha MOC, Pires RFL, Salazar HM, Raso P. Evidência experimental da presença de imunoglobulinas, complemento e antigeno de $S$. mansoni em pulmão de camundongos experimentalmente infectados, e pós-tratamento com oxamniquine - Modelo de doença por imune-complexos. In: Congresso da Sociedade Brasileira de Medicina Tropical, Natal, 1980. Resumos dos trabalhos das sessões de temas livres, aulas e conferências. Natal, RN, p. 169, 1980.

29. Hange LM, Warren KS, Boros DL. S. mansoni: Antigenic secretions and the etiology of egg granulomas in mice. Experimental Parasitology 35: 288-298, 1974.

30. Hiat RA, Ottesen EA, Sotomayor ZR, Lawley TS. Serial observations of circulating immune complexes in patients with acute schistosomiasis. Journal of Infectious Diseases 142:665-670. 1980.

31. Kanamura HY, Hoshino-Shimizu S, Camargo ME, Hidrata MA, Silva LC. Classes de anticorpos e padrões de fluorescência nas formas agudas e crônicas da esquistossomose mansônica. In: Congresso da Sociedade Brasileira de Medicina Tropical, João Pessoa, 1978. Resumos dos trabalhos das sessões de temas livres. João Pessoa, PB, p. 140, 1978.

32. Kniker WT, Guerra FA, Richards SFM. Prevention of immune complex disease (serum sickness) by antagonists of vasoactive amines. Pediatric Research 5: 381 , 1971.

33. Kohler PF. Immune complexes and allergic disease. In: Middleton C Jr, Reed CE, Ellis EF. (ed) Allergy. Principles and Pratice. Mosby CO., Saint Louis, p. 155-176, 1978.

34. Koppisch E. Estudos sobre la esquistossomiasis de Manson en Puerto Rico. IV. Alteraciones anatomopatologicas en el conejo y rata albina inoculados experimentalmente con el S. mansoni. Puerto Rico Journal Health Public and Tropical Medicine 13: 55-114, 1937. 
35. Koppisch E. Studies on schistosomiasis mansoni in Puerto Rico. Morbid anatomy of disease as found in Puerto Ricans. Puerto Rico Journal of Public Health and Tropical Medicine 16: 395-455, 1941.

36. Lawley TJ, Ottesen EA, Hiat RA. Gazze LA. Circulating immune complexes in acute schistosomiasis. Clinical and Experimental Immunology 37: 221-227, 1979.

37. Lichtenberg F von. Raslavicius $P$. Host response to eggs of $S$. mansoni. V. Reactions to purified miracidia and eggs shells and to viable and heat killed whole eggs. Laboratory Investigation 16: 892-904, 1967.

38. Lichtenberg F von, Sher A, Gibbons N, Dougthy BL. Eosinophil-enriched inflammatory response to schistosomula in the skin of mice immune to $S$. mansoni. American Journal of Pathology 84: 479-500, 1976.

39. Lichtenberg F von, Sher A, McIntyre SA. A lung model of schistosome immunity in mice. American Journal of Pathology 87: 105-124, 1977

40. Lunde MM, Ottesen EA, Cheever AW. Serological differences between acute and chronic schistosomiasis mansoni detected by enzyme-linked immunosorbent assay (Elisa). American Journal of Tropical Medicine and Hygiene 28: 87-91, 1979.

41. Mackenzie CD. Ramalho-Pinto FJ, McLaren DJ. Smithers SR. Antibody-mediated adherence of rat eosinophils to schistosomula of $S$. mansoni in vitro. Clinical and Experimental Immunology 30: 97-104, 1977.

42. Magalhàes Fo A. Pulmonary lesion in mice experimentally infected with $S$. mansoni. American Journal of Tropical Medicine and Hygiene 8: 527-535, 1959.

43. Marques RJ. Esquistossomose mansônica, aspectos semiológicos da chamada forma cardiopulmonar. Jornal de Medicina 8: 323-325. 1964.

44. Meira JA. Estudo clinico das formas pulmonares da esquistossomose mansônica (Doença de Manson-Pirajá da Silva). Arquivos da Cirurgia Clinica e Experimental 6: 3-136, 1942.

45. Meira JA. Esquistossomose mansoni hepato-esplênica. Tese de Catedra. Faculdade de Medicina da Universidade de Sào Paulo. SP. 1951.

46. Minard P. Dean DA, Jacobson RH, Vannier WE, Murrell KD. Immunization of mice with cobalt-60 irradiated $S$. mansoni cercariae. American Journal Tropical Medicine and Hygiene 27: 76-86. 1978.

47. Minard P. Dean DA. Vannier WE, Murrell KD. Effect of immunization on migration of $S$. mansoni through lungs. American Journal of Tropical Medicine and Hygiene. 27: 87-93, 1978.

48. Mohamed AS. A fatal case of massive Bilharzia mansoni infection (acute fatal Egyptian splenomegaly). Journal Egyptian Medical Association 19: 749-762, 1936.

49. Moore DV, Sandground JH. The relative egg produzing capacity of $S$. mansoni and $S$. japonicum. American Journal of Tropical Medicine and Hygiene 5: 831-840, 1956.

50. Nash TE. Prescott B. Neva FA. The characteristic of a circulating antigen in schistosomiasis. Journal of Immunology 112: 1500-1507, 1974.
51. Neves J, Raso P. Estudo anátomo-clínico de um caso de forma toxèmica da esquistossomose mansoni que evoluiu para a forma hepatesplènica em 130 dias (fibrose de Symmers). Revista do Instituto de Medicina Tropical de São Paulo 7: 256-266, 1965.

52. Neves J, Raso P, Tafuri WL. Estudo anatomo-clínico de dois casos de forma toxemica da esquistossomose mansoni evoluidos espontaneamente para o óbito. In: Congresso da Sociedade Brasileira de Medicina Tropical, I, Juiz de Fora, 1965. Resumos dos trabalhos das sessōes de temas livres, aulas e conferências. Juiz de Fora, MG, p. 1-100, 1965.

53. Neves J, Lobo-Martins NRL, Tonelli E. Forma toxèmica da esquistossomose mansoni. Consideraçōes diagnósticas em torno de 50 casos identificados em Belo Horizonte. Hospital 70: 143-163, 1966.

54. Neves J, Tonelli E, Carvalho SM. Estudo das manifestaçōes pulmonares da forma toxêmica da esquistossomose mansoni. Revista do Instituto de Medicina Tropical de São Paulo 8: 22-29. 1966.

55. Neves J, Marinho RP, Araujo PKA, Raso P. Spinal cord complications of acute schistosomiasis mansoni. Transactions of the Royal Society Tropical Medicine and Hygiene 67: 782-792, 1973 .

56. Ogilvie BM. Immunoglobulin response in parasitic infections. Proceedings of the Second International Congress of Parasitology. p. 525-534. 1970.

57. Pedroso ERP. Contribuição ao estudo da esquistossomose mansoni humana e experimental. Especial referência às alteraçōes clinico-radiologicas do pulmão após tratamento especifico. Pulmão modelo imunopatológico da doença esquistossomótica. Tese de doutoramento. Faculdade de Medicina da Universidade Federal de Minas Gerais. Belo Horizonte, MG, 1982.

58. Pedroso ERP. Aspectos Clinico-radiológicos da fase aguda da esquistossomose pulmonar. In: Jornada $\mathrm{Mi}$ neira de Radiologia, 2, Belo Horizonte, 1980. Resumos dos trabalhos das sessões de temas livres, aulas e conferèncias. Belo Horizonte. MG. 1980.

59. Pelley RP. Riffies JJ. Warren KS. Suppressive effect of a chronic helminth infection. schistosomiasis mansoni, on the in vitro responses of spleen and lymph node cells to the $\mathrm{T}$ cell mitogens phytohemagglutinin and concanavalin A. Infection and Immunity 13:1176-1183, 1976. 1976.

60. Pifano F. La eosinofilia en la schistosomiasis mansoni. Revista de Sanidad y Asistencia Social 6: 254-296, 1941.

61. Pons JA. Studies on schistosomiasis mansoni in Puerto Rico. Puerto Rico Journal of Public Health and Tropical Medicine 13: 171-254, 1937.

62. Ramalho-Pinto FJ, Mc Laren DJ, Smithers SR. Complement-mediated killing of schistosomula of $S$. mansoni by eosinophils in vitro. Journal of Experimental Medicine 147: 147-156, 1978.

63. Raso P. Bogliolo L. Patologia In: Cunha AS (ed). Esquistossomose mansoni. Cap. 5, p. 77-130, USP, São Paulo, 1970.

64. Raso P, Neves J. Contribuição ao conhecimento do quadro anatômico do figado na forma toxêmica da esquistossomose mansoni através de punções biópsias. 